\title{
Typologie et logique socio-économique des systèmes de culture associant céréales et légumineuses dans les agro-écosystèmes soudano-sahéliens du Burkina Faso
}

\author{
Koulibi Fidèle ZONGO ${ }^{1 *}$, Edmond HIEN ${ }^{1,2}$, Jean-Jacques DREVON ${ }^{3}$, Didier BLAVET ${ }^{2}$, \\ Dominique MASSE$^{2}$ et Cathy CLERMONT-DAUPHIN ${ }^{2}$ \\ ${ }^{1}$ Université de Ouagadougou, Unité de Formation et de Recherche en Science de la Vie et de la Terre \\ (UFR/SVT), 03 BP 7021 Ouagadougou 03, Burkina Faso. \\ ${ }^{2}$ IRD, UMR Ecologie Fonctionnelle \& Biogéochimie des Sols \& Agroécosystèmes (Eco\&Sols), 1 Place Viala, \\ BP 34060, Montpellier, France. \\ ${ }^{3}$ INRA, UMR Ecologie Fonctionnelle \& Biogéochimie des Sols \& Agroécosystèmes (Eco\&Sols), 1 Place Viala, \\ BP 34060, Montpellier, France. \\ *Auteur correspondant; E-mail: fidelezongo62@gmail.com ; Tel : +22678 111810 ; +22671911657.
}

\section{REMERCIEMENTS}

Ce travail a été supporté en partie par le grand projet fédérateur FABATOPIMED, financé par la fondation Agropolis sous la référence ID de 1001 à 009.

\section{RESUME}

Dans la zone soudano-sahélienne du Burkina Faso, les associations mixtes céréales-légumineuses dominent les surfaces cultivées annuellement. Cependant, les rendements sont faibles et ne couvrent souvent pas les besoins alimentaires des exploitations qui les pratiquent. Afin d'améliorer la productivité de ces associations, il est nécessaire de comprendre la logique socio-économique de leurs mises en œuvre. Dans cette optique, 60 exploitations agricoles familiales (EA) ont été enquêtées dans la région Nord du Burkina. Des analyses en correspondances multiples (ACM) font ressortir 4 types de systèmes de culture caractérisés d'une part par le niveau d'apport de matière organique et la fréquence de désherbage et d'autre part, par la présence de structures pérennes de conservation des eaux et des sols. La fertilisation organique et le désherbage fréquent sont associés aux EA les mieux pourvues en main d'œuvre familiale, en petits ruminants et surfaces agricoles. L'âge de l'exploitant agricole et le nombre d'épouses sont de bons indicateurs des moyens économiques de l'EA. La plupart des recettes monétaires annuelles par EA varient dans la gamme très large de 25 à 300 KFCFA. Ces aspects doivent être pris en compte en vue de raisonner des propositions techniques adaptées à la diversité des EA de cette région.

(C) 2016 International Formulae Group. All rights reserved.

Mots clés : ACM, associations mixtes céréales-légumineuses, typologie des systèmes de culture, logique socioéconomique, Burkina Faso.

\section{Typology and socio-economic logic of cropping systems in Sub-Saharan agro-ecosystems of Burkina Faso}

\section{ABSTRACT}

In Sub-Saharan zone of Burkina Faso, legumes and cereals mixed cultivation systems occupy most of the cultivated area. However, yields are low and often do not cover the food needs of farms that practise them. In order to improve the productivity of these intercropping systems, it is necessary to understand the socio- 
economic logic of their implementation. To this purpose, sixty family farms were surveyed in the northern region of Burkina Faso. Multiple correspondences analysis (MCA) showed four types of cropping systems characterized on one hand by the level of organic matter intake and weeding frequency and on the other hand, by the presence of permanent structures for water and soil conservation. Organic matter fertilization and frequent weeding are associated with farms with high family labor, livestock (especially small ruminants) and high cultivated area, while $70 \%$ of farmers have an off-farm activity. The age of household head and the number of their wives are good indicators of farmers' income. Most of farmers' monetary recipes vary widely from 25 to 300 KFCFA. These aspects must be taken into consideration for reasoning suitable technical recommendations for the farmer's in this region.

(C) 2016 International Formulae Group. All rights reserved.

Keywords: MCA, legumes and cereals mixed cultivation systems, typology of cropping systems, socio-economic logic, Burkina Faso.

DOI : http://dx.doi.org/10.4314/ijbcs.v10i1.23

\section{INTRODUCTION}

Les associations vivrières céréaleslégumineuses occupent plus de $80 \%$ des surfaces cultivées dans la zone soudanosahélienne du Burkina Faso et sont à la base de l'alimentation humaine (DPSAA, 2011). Ces associations sont généralement développées dans de petites exploitations familiales disposant d'une surface agricole moyenne de moins de 4 ha, et de peu de capital pour l'achat d'intrants chimiques. Avec des rendements moyens de moins de $0,4 \mathrm{t} \mathrm{ha}^{-1}$ pour le sorgho ou le mil et $0,2 \mathrm{t} \mathrm{ha}^{-1}$ pour le niébé, ces associations sont considérées comme peu productives (Aune et Bationo, 2008; Bambara et al., 2008; Dabat et al., 2012).

Les modes de conduite de ces associations céréales-légumineuses présentent des différences notables en fonction des régions. Même dans une petite région homogène par les sols et le climat, une diversité de gestion des nutriments conduisant parfois à des niveaux de fertilité contrastés a été mise en évidence par Mazzucato et Niemeijer (2000) pour l'Est Burkina Faso, Wopereis et al. (2006) pour le Nord Togo, Affholder et al. (2013) pour le bassin arachidier au Sénégal et Chikowo et al. (2014) pour l'Afrique de l'Est. De même, Fatondji et al. (2001), Zougmoré et al. (2004), Sawadogo et al. (2008), Hien et al. (2010), Bayala et al. (2012) mentionnent l'existence d'une diversité de pratiques locales de conservation des eaux et des sols en Afrique soudanosahélienne. Giller et al. (2009), Serpantié (2009), Lahmar et Yacouba (2012) signalent la présence de mulch ligneux sur certaines parcelles du Burkina Faso. La diversité des rotations et des associations culturales sur les parcelles sont d'autres facteurs éventuels de variabilité des systèmes de culture céréaleslégumineuses en zone soudano-sahélienne (Bado et al., 2006; Bationo et al., 2012; Bayala et al., 2012; Zeinabou et al., 2014). Cependant, si la variabilité des techniques prises isolément est bien connue, l'on dispose de peu de références pour comprendre comment les agriculteurs d'une petite région raisonnent leurs choix techniques les uns par rapport aux autres, et pour classer les systèmes de culture ou modes de conduite technique en différents types ayant des logiques spécifiques.

De nombreux travaux rapportent que les systèmes de culture rencontrés dans les agricultures familiales concilient souvent à la fois une logique technique et socioéconomique (Somda et al., 2002; Ouédraogo, 2004; Mowo et al., 2006; Affholder et al., 2013; Chikowo et al., 2014; Koura et al., 2015 ). Des contraintes socio-économiques 
peuvent justifier le rejet de propositions techniques pourtant performantes au plan de la production (Ondersteijn et al., 2003; Clermont-Dauphin et al., 2013). Dans la perspective d'une meilleure prise en compte des facteurs socio-économiques dans les démarches d'amélioration des systèmes de culture dans la région Nord du Burkina Faso, cette étude vise à établir une typologie de systèmes de culture et à mettre à jour les liens entre les différents types identifiés et des variables de caractérisation socio-économique des exploitations agricoles.

\section{MATERIEL ET METHODES}

\section{Présentation de la région d'étude}

L'étude a été menée dans 4 villages des 4 provinces de la région Nord du Burkina Faso (Figure 1) : Pougyango dans la province du Passoré $\left(12^{\circ} 58^{\prime} \mathrm{N}, 2^{\circ} 08^{\circ} \mathrm{O}\right)$, Zindiguéssé dans le Zandoma $\left(13^{\circ} 16^{\prime} \mathrm{N}, \quad 2^{\circ} 20^{\prime} \mathrm{O}\right)$, Soumyaga dans le Yatenga $\left(13^{\circ} 30^{\prime} \mathrm{N}, 2^{\circ} 24^{\prime} \mathrm{O}\right)$ et Titao dans le Lorum $\left(13^{\circ} 45^{\prime} \mathrm{N}, 2^{\circ} 05^{\prime} \mathrm{O}\right)$.

Ces villages ont été considérés comme représentatifs de la diversité des conditions pédo-climatiques régionales. Le climat est de type soudano-sahélien dominé par l'influence des vents d'harmattan et de mousson. Il est caractérisé par l'alternance de 2 saisons : une longue saison sèche d'octobre à mai et une courte saison pluvieuse de juin à septembre où se concentre $90 \%$ de la pluviométrie annuelle (Figure 1). Les températures moyennes mensuelles les plus élevées sont de $35 \pm 5{ }^{\circ} \mathrm{C}$ durant avril et mai. Les plus faibles sont de $25 \pm 4{ }^{\circ} \mathrm{C}$ durant décembre et janvier (Figure 1). Sur la période 2000-2013, la pluviométrie annuelle a varié dans les gammes de 500 à $900 \mathrm{~mm} \mathrm{an}^{-1}$ avec une moyenne de $715 \pm 108$ mm. Les principaux types de sols sont des leptosols ferriques, pétro-ferriques et des lixisols (FAO, 2014). Ils sont soumis à une forte érosion hydrique en raison de leur position physiographique et du manque de couvert végétal. Sur le plan physique, ils sont majoritairement graveleux et présentent une texture sablo-limoneuse à argileuse en profondeur. Au niveau chimique, on note des carences en azote et en phosphore, des $\mathrm{pH}$ acides et des teneurs en matière organique souvent inférieures à $1 \%$ (FAO, 2000). La végétation naturelle est formée de steppes, brousses tigrées, savanes arbustives à arborées et savanes ripicoles, bien décrites par Guinko (1998).

\section{Enquêtes sur les systèmes de culture et leurs déterminants socio-économiques Conception du questionnaire, échantillonnage et collecte des données}

Ces enquêtes ont été effectuées à l'échelle de l'exploitation agricole familiale (EA). Celle-ci représente une unité de production, de consommation et de résidence sous la responsabilité du chef de famille qui prend les décisions de gestion de l'entité. Le plan de sondage a consisté en une enquête par sondage aléatoire. Dans chaque province, le choix du village a été fait de manière aléatoire sans tenir compte du nombre total de villages de la province. Ensuite, dans chaque village «échantillon», quinze (15) exploitations agricoles ont été choisies de manière aléatoire, quel que soit le nombre d'exploitations agricoles dans le village. Ce plan de sondage peut être considéré comme un échantillonnage stratifié non proportionnel. Cette approche permet d'avoir une meilleure représentation de la diversité des réponses, la réduction des coûts et de la charge de travail. Soixante (60) EA ont donc été enquêtées. La collecte des données s'est effectuée en deux phases, de mai 2012 à septembre 2012 : premièrement, 5 chefs d'EA par village ont été soumis à un questionnaire test conçu de manière semistructurée en se basant sur des connaissances et des données générales déjà existantes sur la zone d'étude. Après cette phase test et en 
fonction des réponses recueillies, certaines rubriques du questionnaire ont été modifiées afin de mieux l'adapté au contexte de l'étude. A cet effet, des questions ont été réajustées, rajoutées et même approfondies. Ensuite, dans une deuxième étape, 15 EA par village y compris les 5 déjà enquêtés durant la phase test, ont été soumises au nouveau questionnaire considéré comme le mieux adapté. Durant ces enquêtes, des observations directes ont été aussi réalisées sur le terrain : présence éventuelle de fosses fumières, matériels agricoles, animaux de trait et d'élevage, techniques anti-érosives dans les champs.

\section{Caractérisation des systèmes de culture}

$\mathrm{La}$ caractérisation des systèmes de culture s'appuie sur des variables ou indicateurs considérés comme les plus susceptibles d'entraîner des différences de performances et d'être en lien avec le contexte socio-économique de l'exploitation agricole. Ces variables sont: les superficies annuelles allouées aux associations (sas); la diversité de culture des associations pendant une même campagne agricole (idc); la présence des techniques de conservation des eaux et des sols et de défense et restauration des sols (ces) ; les doses $\left(\mathrm{t} \mathrm{ha}^{-1} \mathrm{an}^{-1}\right)$ de compost (com) et de fumier (fum); la pratique de traitements phytosanitaires (tp); les quantités $\left(\mathrm{kg} \mathrm{ha}^{-1} \mathrm{an}^{-1}\right)$ de NPK (npk) apportés; la fréquence de désherbage annuel (fd); les rendements moyens (selon les dires des chefs d'EA) des céréales (mil et sorgho) (rdc) et du niébé (rdn) à l'ha. Tenant compte de la faible variabilité entre les parcelles d'une même exploitation, une note moyenne par exploitation a été considérée pour chaque variable. La signification de chaque note apparait dans le Tableau 1.
Caractérisation socio-économiques des exploitations agricoles

La caractérisation socio-économique des exploitations agricoles (EA) s'appuie sur 2 jeux de variables collectées par enquête: d'une part des variables (ou indicateurs) de «statut social»: l'âge du chef d'exploitation (ag); le nombre d'épouses (ne); la scolarité (sc) et le niveau de scolarisation (ns); l'alphabétisation (al); la langue d'alphabétisation (m); le nombre de bouches à nourrir (bn) (Tableau 2); d'autre part, des variables économiques: le nombre total des champs (ntc); la superficie totale des champs (stc); le nombre d'actifs agricoles (naa); le niveau d'équipements agricoles (eqa) caractérisé par le nombre de bovins de trait, de charrues, de charrettes et d'ânes; le nombre de petits ruminants (pr) : ovins et caprins; le nombre de bovins d'élevage (be); le nombre de volailles (vo): poules et pintades; l'existence ou non d'activités secondaires (as); les recettes monétaires annuelles (rae) soit la somme des entrées d'argent d'origine agricole ou non (Tableau 3).

\section{Analyses statistiques des données}

Les variables expliquées dans cette étude sont les caractéristiques de systèmes de culture et les variables explicatives testées sont les caractéristiques socio-économiques des exploitations telles que décrites par les indicateurs ci-dessus. Les analyses statistiques suivantes ont été réalisées :

- une Analyse en Correspondances Multiples (ACM) sur les variables de caractérisation des systèmes de culture afin d'identifier les indicateurs les plus pertinents de différenciation des systèmes de culture et donc d'établir une typologie des systèmes de culture. Dans cette analyse, les rendements ( $r d c$ et $r d n)$ ont été projetés en variables supplémentaires. 
- des ACM sur les variables de statut social des EA d'une part, et économiques d'autre part. Ces analyses ont permis de dégager les variables les plus représentatives de la diversité des situations sociales et économiques et d'établir une typologie des EA. Dans ces analyses, les recettes monétaires annuelles (rae) ont été projetées en variable supplémentaire.

- deux ACM sur les relations entre les groupes de variables identifiées au cours des deux étapes précédentes. Dans une première étape, les variables sociales (ag et ne) qui discriminent mieux les différents groupes, ont été projetées comme variable supplémentaires sur l'ACM des variables économiques. Dans une deuxième étape, les variables économiques (stc, naa, be, pr, vo) les plus représentatives de différents groupes économiques ont été à leurs tours projetées sur l'ACM des variables de systèmes de culture.

La plupart des variables ont été regroupées en 2 ou 3 classes de modalités pour former des variables qualitatives pertinentes pour l'interprétation (Kuentz et al., 2013). Les variables projetées comme supplémentaires ne participent pas à la formation des axes de l'ACM. Elles sont traitées comme des variables synthétiques, susceptibles d'expliquer ou d'être expliquées par un ensemble d'autres variables.

Les groupes d'EA (G1, G2, G3 etc.) ont été formés en se basant sur des critères objectifs de proximité et de liaison des modalités qui constituent le groupe. Aussi, l'opposition des groupes de modalités par rapport à chaque axe des ACM a été considérée comme un critère de distinction de groupes différents. Le logiciel statistique STATISTICA 7 utilisé a été à cet effet.

\section{RESULTATS}

\section{Caractéristiques des systèmes de culture}

Les associations mil-niébé, sorghoniébé ou sorgho-mil-niébé représentent plus de $80 \%$ des parcelles cultivées de la plupart des EA (Tableau 1). Soixante-sept pourcent $(67 \%)$ des EA mettent en place des associations de deux espèces exclusivement : sorgho-niébé ou mil-niébé. Ces associations sont pratiquées tous les ans. Au cours de la saison sèche, les parcelles sont livrées à la vaine pâture bovine, ovine et caprine.

La campagne agricole commence en mai-juin par la préparation des lits de semences (Figure 2). Cette activité consiste à couper des épineux et autres arbustes qui se sont développés pendant la saison sèche et à les épandre sur les surfaces encroûtées des champs. Sur les terres peu ou non encroûtées, un labour avec la charrue attelée à un animal de trait (bovins, ânes) est réalisé entre mi-juin et fin juillet, généralement après une pluie. Sur les terres les plus dégradées appelées «zippélés » dans la région, le creusement des cuvettes de zaï est pratiqué avec la pioche ou la daba de mai à mi-juin (Figure 2). Le zaï est une technique traditionnelle de mise en culture des sols encroûtés. Cette technique déjà décrite notamment par Sawadogo et al. (2008), Hien et al. (2010) consiste à effectuer les semis au niveau des cuvettes de 20 à 40 $\mathrm{cm}$ de diamètre et de 10 à $15 \mathrm{~cm}$ de profondeur. Les trous sont distants de 0,5 à 1 $\mathrm{m}$. Le déblai est déposé en forme de croissant vers l'aval pour capter les eaux de ruissellement. Les trous creusés en saison sèche reçoivent du fumier et/ou du compost et/ou des résidus d'ordures ménagères en attendant la pluie. Les termites, attirées par la matière organique, creusent des galeries et l'incorporent au sol. Les semences sont déposées dans les cuvettes de zaï à sec ou dès qu'elles ont assez d'eau. Les effets du zaï sur l'amélioration de la fertilité physique, 
chimique et biologique des sols, et sur les rendements des cultures ont été largement documentés (Roose, 2004 ; Zougmoré et al., 2004; Sawadogo et al., 2008; Hien et al., 2010; Doamba et al., 2011 ; Somé et al., 2015). D'autres structures plus ou moins pérennes de conservation des eaux et des sols ou de défense et restauration des sols sont parfois développées sur les parcelles: les cordons pierreux, les demi-lunes, les bandes enherbées (Figure 3). Les cordons pierreux sont des barrières de pierres disposées dans des tranchées de 10-15 cm de profondeur et d'environ 15-20 cm de largeur suivant des courbes de niveau (Figure 3). Ils permettent d'arrêter ou de freiner les eaux de ruissellement en réduisant l'érosion et en augmentant le stock d'humidité du sol. Les demi-lunes sont des cuvettes en demi-cercle de 2 à $3 \mathrm{~m}$ de rayon et de 30 à $40 \mathrm{~cm}$ de profondeur creusées et ceinturées avec les déblais disposés en arc de cercle ouvert en amont (Figure 3). Le creux recueille l'eau piégée à l'amont de la demi-lune permettant aux plantes cultivées de recevoir beaucoup plus d'eau que ne leur apportent directement les pluies. Les bandes enherbées sont des bandes de végétation permanentes établies perpendiculairement au sens des écoulements diffus des eaux le long des courbes de niveau dans les champs (Figure 3). Elles permettent la filtration/dépôt des nutriments, matières organiques et sédiments, la réduction du ruissellement. Ainsi que l'indique le Tableau 1, la combinaison du zaï et des cordons pierreux (ces2) est fréquente au sein des champs de $58 \%$ des EA.

Cinquante-trois pourcent (53\%) des EA effectuent sur les billons de labour ou les poquets de zaï des apports de compost (com1) inférieurs à $0,5 \mathrm{t} \mathrm{ha}^{-1}$ et $47 \%$ utilisent des quantités allant de 0,5 à $1,5 \mathrm{t} \mathrm{ha}^{-1}$ (Tableau 1). Les composts sont généralement faits d'un mélange de fumier, d'ordures ménagères et de restes d'aliments du bétail rassemblés dans des fosses fumières ou entassés pendant la saison sèche. Le compost est parfois complété ou remplacé par du fumier provenant des déjections d'animaux collectées autour des concessions et directement transporté dans les champs. Le compost et/ou le fumier sont apportés en une seule fois en début de campagne et ne sont pas enfouis.

Après la phase de préparation, les semis sont effectués à sec ou après une pluie fin juin-début juillet. Les lignes de semis, en zaï ou sur billons de labour, sont écartées de 0,5 à $0,8 \mathrm{~m}$ et les écartements sur la ligne varient entre 0,4 et $0,5 \mathrm{~m}$. Environ 10 graines de sorgho ou de mil et 4 graines de niébé (de manière aléatoire) sont semées dans les poquets de zaï ou des billons de labour pour réduire leur possible destruction par les insectes granivores des sols et minimiser les risques de faible germination dû au déficit hydrique. Les semences utilisées sont des semences fermières. Les variétés de céréales sont à hautes tiges avec un cycle semismaturité de 115 à 120 jours. Les variétés de sorgho utilisées sont appelées en langue locale, le moorée «kapelga», «sayoro», «fibmiougou» et celles de mil «bèblaada», «balbou» et «kassablega». Le niébé est rampant avec une floraison échelonnée sur 15 jours environ. Il arrive à maturité entre 80 à 90 jours après semis. Les variétés locales de niébé «being raaga», «kome callé», «being sablega», «being ramiougou» sont les plus utilisées dans l'association. Avant la mise en terre des semences, $87 \%$ des EA les enrobent avec des insecticides (tp2, Figure 2) principalement le Calthio C, l'Imidalim-T 450 WS et le Caïman Rouge P.

Environ 25 à 30 jours après semis (fin juillet-début août), si la pluviométrie n'a pas permis un taux de levée satisfaisant, des resemis des céréales et du niébé sont effectués. Environ 15 à 20 jours après levée, un 
démariage-repiquage manuel a lieu pour réduire à 3 environ le nombre de plantules de céréales par poquet (Figure 2). 60\% des EA font 2 à 3 désherbages (fd1) manuels au cours du cycle de l'association et $40 \%$ plus de 3 (Tableau 1). Le désherbage est fait avec la daba, la charrue ou la houe manga tractée par les bovins ou des ânes. La durée du désherbage est moins importante avec le zaï sur les «zippélés» car les adventices poussent peu sur ces sols encroûtés.

L'apport d'engrais chimiques généralement effectué au moment du désherbage, est rare. Des apports supérieurs à $10 \mathrm{~kg} \mathrm{ha}^{-1}$ (npk2) ne sont réalisés que dans $33 \%$ des EA (Tableau 1). Les intrants chimiques utilisés sont de formulation 15-1515 (N-P-K), la plus utilisée ou 23-10-5 comprenant $2 \mathrm{MgO}, 3 \mathrm{~S}$ et $0,3 \mathrm{Zn}$.

Enfin, la récolte du niébé intervient miseptembre-début octobre, soit un mois avant celle des céréales (Figure 2). Les rendements sont inférieurs à $0,3 \mathrm{t} \mathrm{ha}^{-1}$ pour les céréales (rdc1) dans $83 \%$ des EA et à $0,2 \mathrm{t} \mathrm{ha}^{-1}$ pour le niébé (rdn1) dans 90\% des EA.

\section{Caractéristiques socio-économiques des exploitations agricoles}

\section{Statut social}

Cinquante-deux pourcent $(52 \%)$ des chefs d'EA ont entre 40 et 60 ans (ag2), 18\% ont moins de 40 ans (ag1) et $30 \%$ ont plus de 60 ans (Tableau 2). Ils sont tous de sexe masculin, essentiellement musulmans, de l'ethnie mossé et autochtones de la région. $25 \%$ des chefs d'EA enquêtés ont moins de 2 épouses (ne1), $47 \%$ en ont 2 à 3 (ne2) et $28 \%$ ont plus de 3 épouses (ne3). 58\% sont scolarisés (sc2) principalement avec le niveau primaire (ns2). 43\% sont alphabétisés en mooré ou en arabe (Tableau 2). Plus de la moitié des chefs d'EA (52\%) ont entre 10 et 20 bouches à nourrir (bn2). $25 \%$ en ont moins de 10 et $23 \%$ en ont plus de 20 (Tableau 2).
Par ailleurs, plus le chef des EA est âgé plus son exploitation est ancienne.

\section{Statut économique}

Soixante-huit pourcent $(68 \%)$ des EA ont entre 3 et 5 ha (stc2) et seulement $18 \%$ ont une surface supérieure (Tableau 3). Le nombre de champs est distribué entre 1 et 6 . La main d'œuvre utilisée dans l'EA est essentiellement familiale et $55 \%$ des EA possèdent moins de 8 actifs agricoles (+12ans). Vingt-huit pourcent (28\%) des EA ont entre 8 et 15 actifs agricoles (naa2) et $17 \%$ plus de 15 (Tableau 3). Les chefs d'EA estiment que dès 12 ans, les enfants peuvent participer aux travaux agricoles. Les travaux ont lieu pendant les vacances scolaires, ce qui permet la participation des enfants scolarisés.

Trente-huit pourcent (38\%) des EA ont 2 équipements différents (eqa2) et $42 \%$ possèdent plus de 3 équipements (eqa3). Ces équipements sont généralement le bovin de trait, la charrette, la charrue et l'âne.

L'élevage est aussi pratiqué au sein des EA. Les petits ruminants (pr1, pr2 et pr3) et la volaille (vo1, vo2, vo3) dominent dans les élevages. Le cheptel bovin est inexistant chez $70 \%$ des EA (be1); $22 \%$ des EA ont entre 1 et 7 bovins d'élevage (be2) et seulement $8 \%$ en possèdent entre 7 et 20 (be3).

Une activité extra-agricole ou secondaire (as2) est menée par 70\% des chefs d'EA. Ces activités sont par ordre d'importance, l'orpaillage, le commerce, l'artisanat, la mécanique, la couture. Les recettes monétaires moyennes annuelles de $52 \%$ des EA sont comprises entre 100 à 300 KFCFA (rae2) soit 152,45 à 457,35 euros (Tableau 3). Seulement 22\% des EA ont des revenus supérieurs à $300 \mathrm{KCFA}$ (rae3).

\section{Analyse en correspondances multiples Variables de système de culture \\ L'ACM pratiquée sur les variables de système de culture montre que les 2 premiers}


axes expliquent $45 \%$ de la variance totale de l'échantillon (Figure 4). L'axe 1 oppose les systèmes de culture où les quantités de fumier apportées et la fréquence de désherbage sont minimaux (fum1, fd1), et ceux où ces variables sont maximaux (fum2, fd2). L'axe 2, par contre, oppose les systèmes de culture où les techniques de CES/DRS sont multiples (ces2), et ceux où elles sont minimales (ces1). L'apport d'engrais chimiques NPK (npk1, npk2) est intermédiaire entre les groupes formés par les axes principaux. Les systèmes de culture de l'association céréales-niébé peuvent donc être classés en quatre types (G1, G2, G3 et G4) dont les caractéristiques techniques sont résumées dans le Tableau 4 sous les dénominations de «Peu intensif et peu aménagé» pour le G1, «Intensif et peu aménagé» pour le G2, «Peu intensif et aménagé» pour le G3 «Intensif et aménagé» pour le G4.

Les rendements (rdc1, rdc2, rdn1) ne participent pas à la formation des deux axes. Cependant, les meilleurs rendements de niébé (rdn2) sont liés à la pratique du zaï en plus des cordons pierreux (ces2) et aux faibles apports d'engrais NPK (npk1).

\section{Variables de statut social et économique}

La Figure 5 présente l'ACM appliquée sur les variables de statut social. 50\% de la variance est expliquée par les 2 axes. Trois groupes d'EA se distinguent sur cette ACM: i) un premier groupe d'EA (G1) où les chefs d'EA ont moins de 40 ans (ag1), moins de 2 épouses (ne1) et seulement 3 à 10 personnes à leurs charges (bn1); ii) un deuxième groupe (G2) où les chefs d'EA ont entre 40 et 60 ans (ag2), avec 2 à 3 épouses (ne2) et entre 10 et 20 bouches à nourrir; et iii) un troisième groupe (G3) où les chefs d'EA ont plus de 60 ans (ag3), 4 à 5 épouses (ne3) et plus de 20 bouches à nourrir (bn3). Ainsi, plus le chef de l'EA est âgé (ag3), plus celui-ci a d'épouses (ne3) et de bouches à nourrir (bn3).
La Figure 6 présente l'ACM appliquée sur les variables économiques. Trente-trois pourcent $(33 \%)$ de la variance est expliquée par les 2 axes. Trois groupes d'EA se distinguent sur le plan économique: i) un premier groupe d'EA (G1) ayant le moins de superficies (stc1), d'équipements agricoles (eqa1) et d'actifs agricoles (naa1), de petits ruminants (pr1), aucun bovin d'élevage (be1) et 10 à 20 volailles (vo2); ii) un deuxième groupe (G2) plutôt intermédiaire pour la plupart de ces variables; et iii) un troisième groupe (G3) ayant le plus de superficies totales des champs (stc3) et d'équipements agricoles (eqa3), 8 à plus de 15 actifs agricoles (naa2, naa3), plus de bovins d'élevage (be3), de petits ruminants (pr3) et de volailles (vo3). Trois niveaux de recettes monétaires sont associés à ces 3 trois groupes économiques d'EA: i) les plus faibles recettes monétaires, moins de 100 KFCFA (rae1), plutôt associés au deuxième groupe; ii) les recettes comprises entre 100 à 300 KFCFA (rae2) associés au premier groupe; et iii) les recettes supérieurs à 300 KFCFA (rae3) associés aux EA les mieux pourvus en moyens de production. Une activité secondaire ou extra-agricole (as2) semble associée au deuxième et au troisième groupe d'EA.

\section{Relation entre variables sociales, économiques et de systèmes de culture}

La Figure 7 montre pour tendance générale que les chefs d'EA les plus âgés (ag3), sont les plus nantis économiquement, avec des surfaces totales (stc3), et une disponibilité en main d'œuvre plus élevées (naa2, naa3) ; ces chefs d'EA ont plus d'épouses (ne3), d'équipements agricoles (eqa3), de petits ruminants (pr3) et de volailles (vo3) (G1). Les deux autres groupes d'âge (ag2 et ag1) ne se distinguent pas clairement sur le plan économique.

La Figure 8 présente les relations entre variables de système de culture et 
économiques. Il ressort que les systèmes de culture les moins intensifs tels que décrits dans la section sur l'ACM des variables de système de culture, sont associés aux EA les moins nanties économiquement (G1), et que les systèmes de culture les plus intensifs sont associés aux exploitations les plus nanties (G2). L'élevage de volailles est privilégié principalement quand l'élevage de bovins ou de petits ruminants ne semble pas possible et où les disponibilités de main d'œuvre et de surface sont les plus faibles. La typologie des systèmes de culture et les caractéristiques socio-économiques associées sont récapitulées dans le Tableau 4.

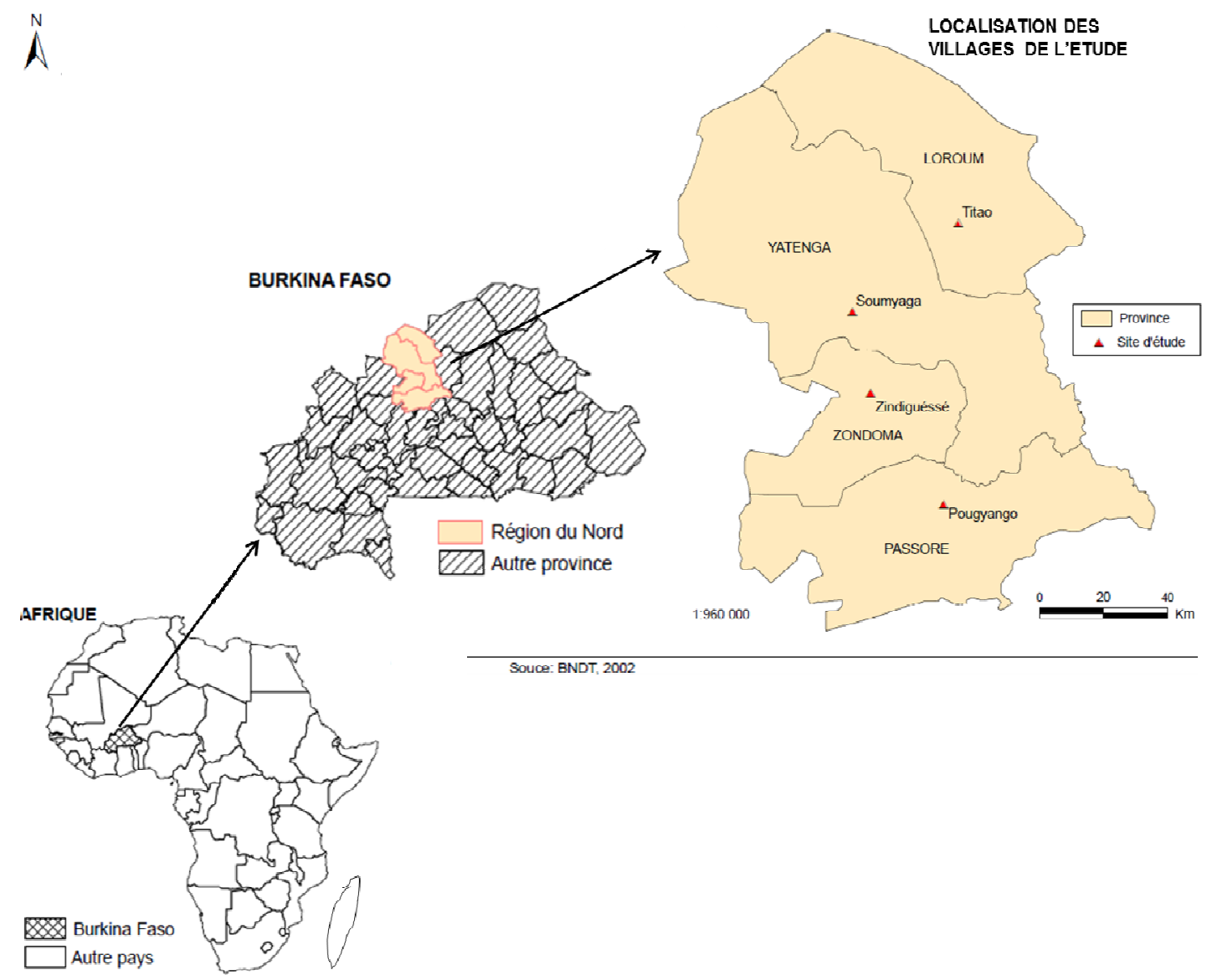

Figure 1 : Localisation et caractéristiques climatiques de la zone de l'étude (les variations mensuelles de la pluviométrie et de la température sont de 2000 à 2013 ; source des données climatiques. Direction Générale de la Météorologie/Ouagadougou, Burkina Faso ; source des données cartographiques : Base Nationale de Données sur le Territoire/Ouagadougou, Burkina Faso). 

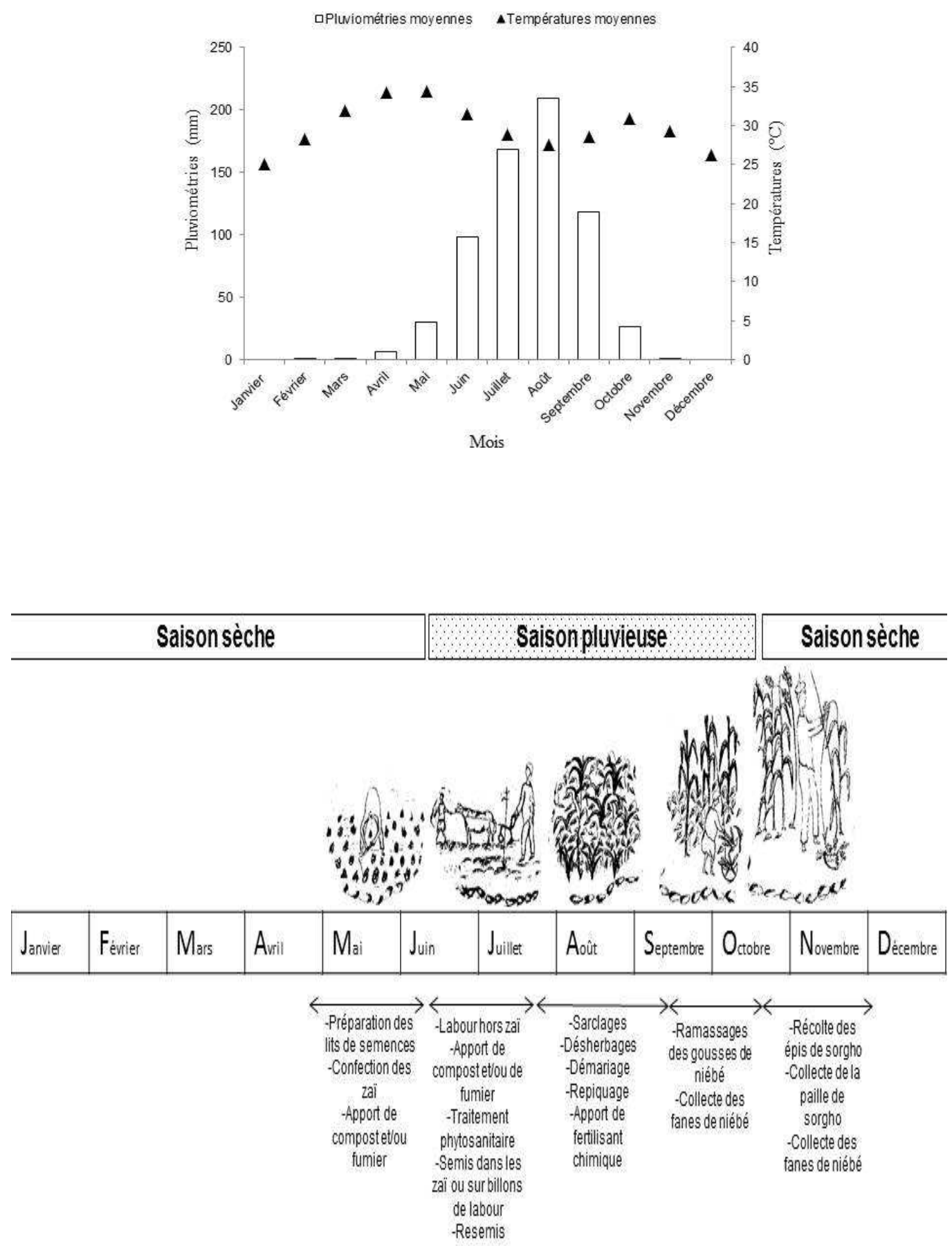

Figure 2 : Calendrier des pratiques culturales des associations céréales-légumineuses. 

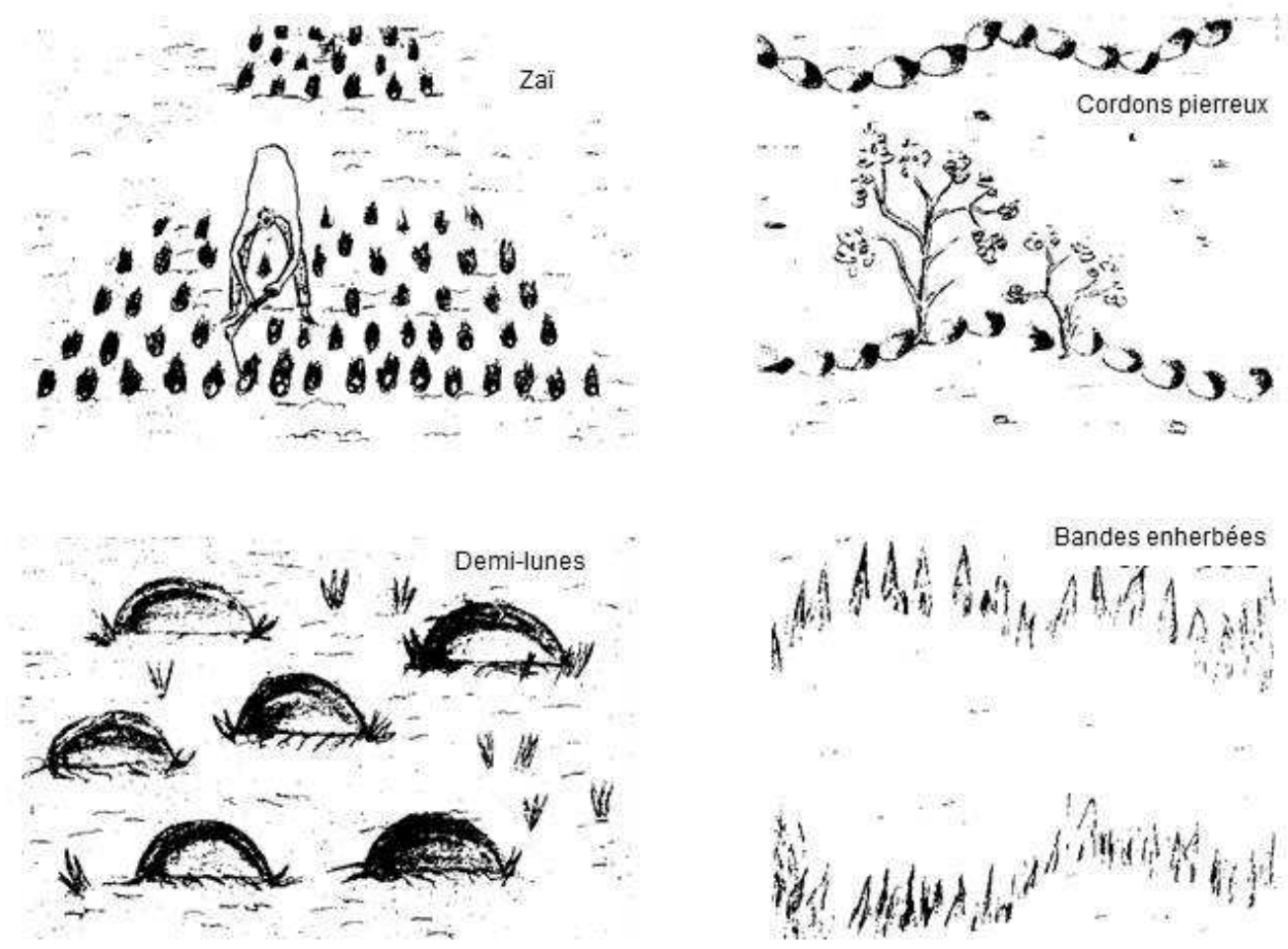

Figure 3 : Techniques de conservation des eaux et des sols et de défense restauration des sols.

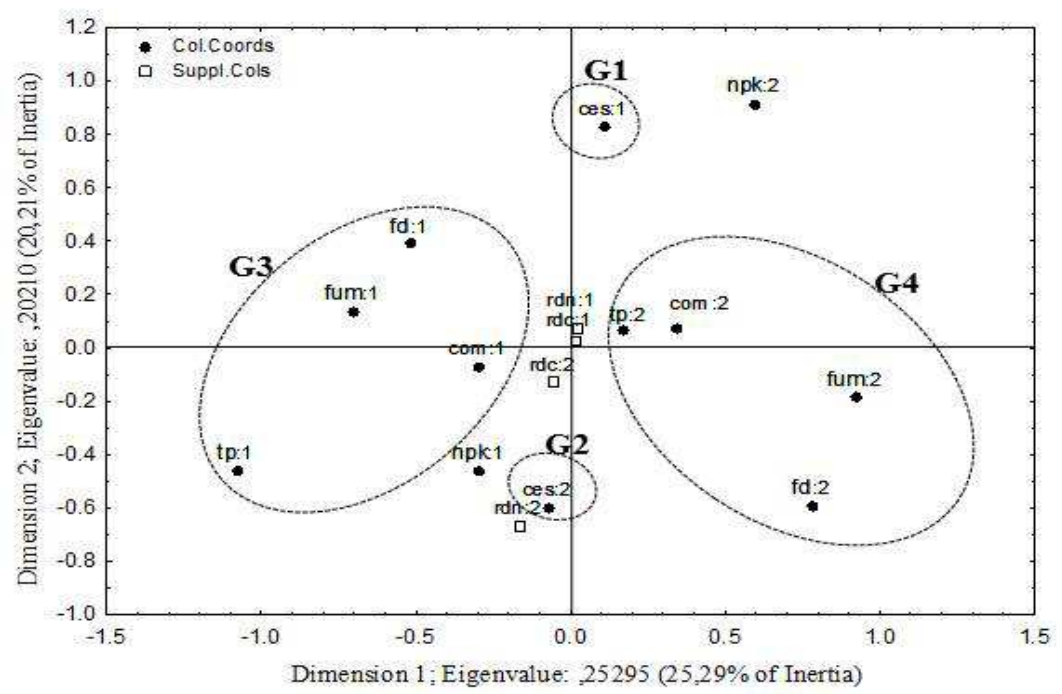

Figure 4 : Analyse en correspondances multiples des variables de systèmes de culture. EA: exploitation agricole; n: nombre d'exploitation agricole; CES/DRS: conservation des eaux et des sols et de défense restauration des sols; CP: cordons pierreux, BE: bandes enherbées; DL: demi-lunes ; G: groupe d'exploitations agricoles établis par un ensemble de modalités de variables. 


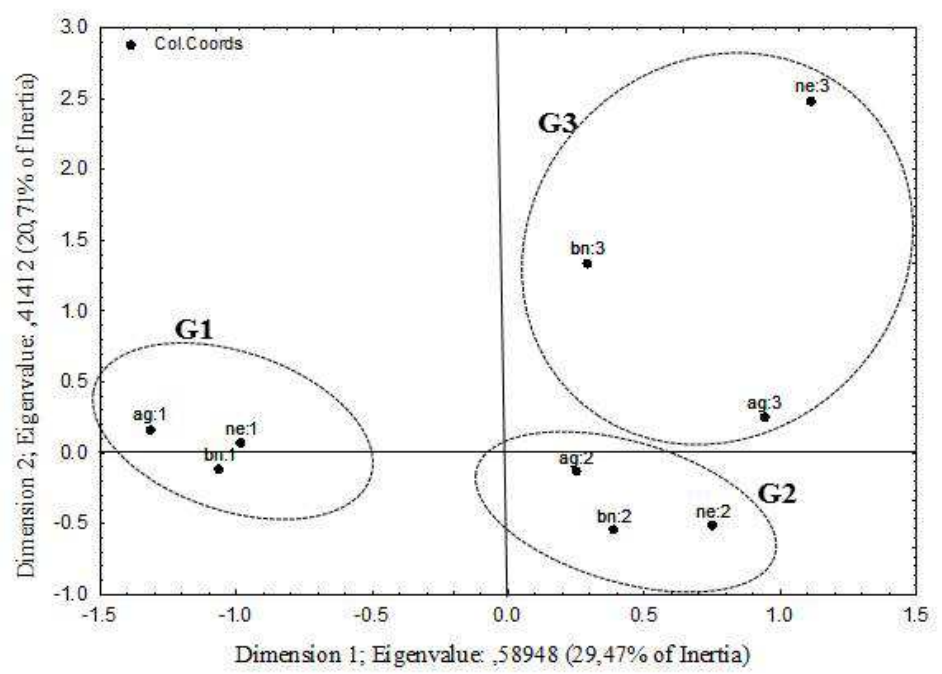

Figure 5 : Analyse en correspondances multiples des variables de statut social (les abréviations indiquées pour les variables sont décrites dans le Tableau 2).

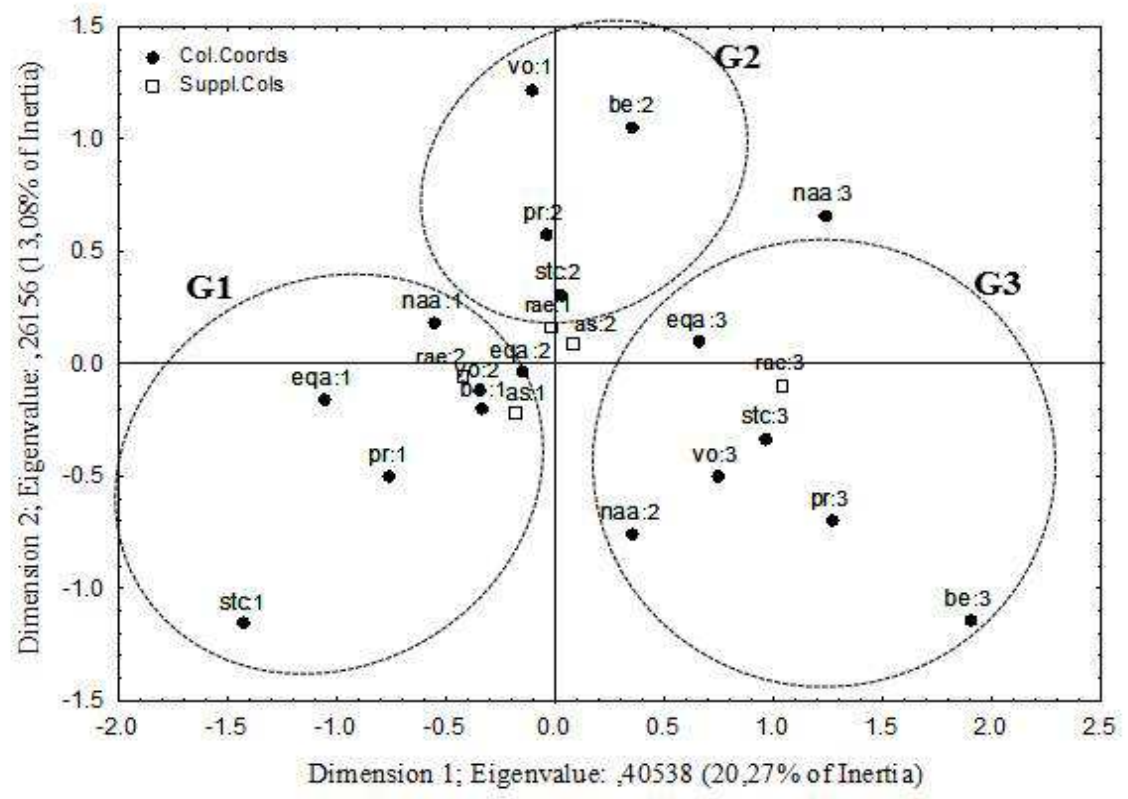

Figure 6 : Analyse en correspondances multiples des variables économiques (les abréviations indiquées pour les variables sont décrites dans le Tableau 3). 


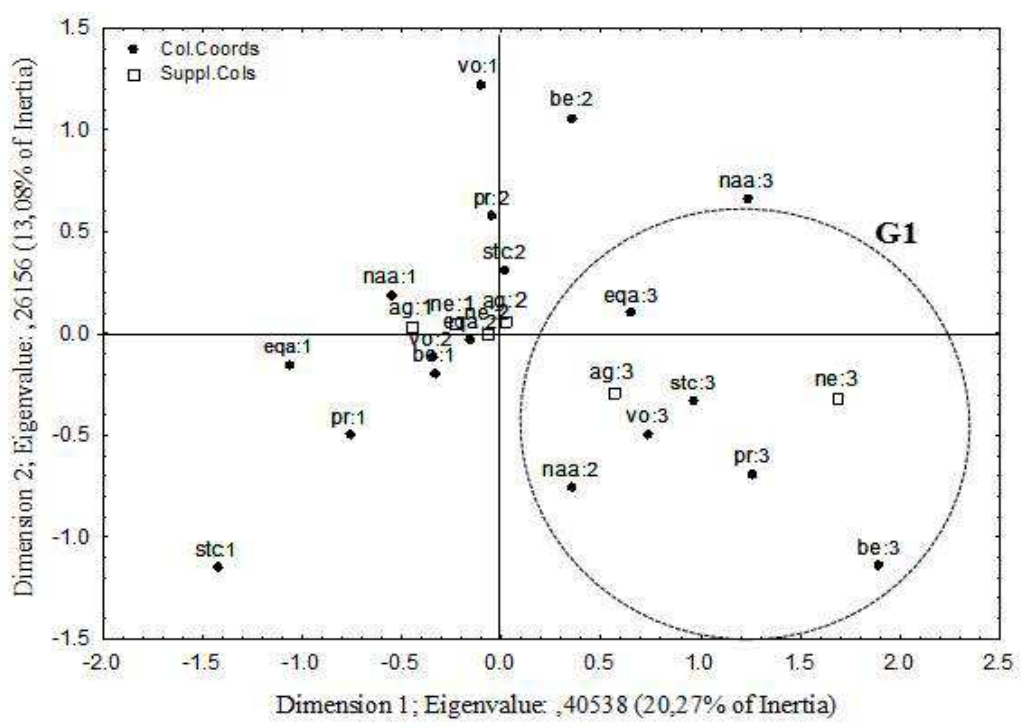

Figure 7 : Relation entre variables social et économique (les abréviations indiquées pour les variables sont décrites dans les Tableaux 2 et 3 ).

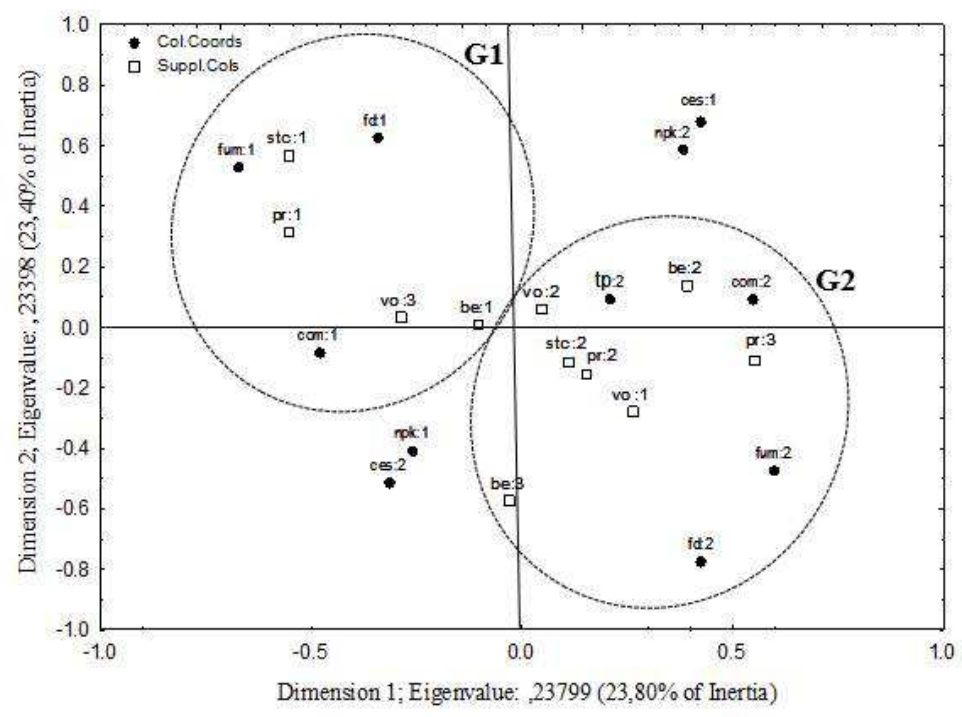

Figure 8 : Relation entre variables de système de culture et économique (les abréviations indiquées pour les variables sont décrites dans les Tableaux 1 et 3 ). 
Tableau 1 : Variables des systèmes de culture des exploitations agricoles.

\begin{tabular}{|c|c|c|c|c|}
\hline Systèmes de culture & Notes & Indicateurs & Nombre d'EA & $\begin{array}{c}\text { Pourcentage d'EA } \\
(\mathbf{n}=60)\end{array}$ \\
\hline \multicolumn{5}{|c|}{ Superficies annuelles allouées aux associations } \\
\hline 50 à $80 \%$ & 1 & sas1 & 12 & $20 \%$ \\
\hline plus de $80 \%$ & 2 & sas2 & 48 & $80 \%$ \\
\hline \multicolumn{5}{|l|}{$\begin{array}{l}\text { Diversification des associations } \\
\text { pendant la même campagne agricole }\end{array}$} \\
\hline sorgho-niébé et/ou mil-niébé & 1 & idc1 & 40 & $67 \%$ \\
\hline sorgho-mil-niébé & 2 & idc2 & 11 & $18 \%$ \\
\hline sorgho-niébé, mil-niébé et sorgho-mil-niébé & 3 & idc3 & 9 & $15 \%$ \\
\hline \multicolumn{5}{|l|}{ Techniques de CES/DRS } \\
\hline Zaï ou CP ou BE ou DL & 1 & ces 1 & 25 & $42 \%$ \\
\hline Zaï+CP & 2 & ces 2 & 35 & $58 \%$ \\
\hline \multicolumn{5}{|l|}{ Quantité de compost (t.ha $\left.{ }^{-1} \cdot \mathrm{an}^{-1}\right)$} \\
\hline minimum: $[0,2 ; 0,5[$ & 1 & com1 & 32 & $53 \%$ \\
\hline maximum: $[0,5 ; 1,5]$ & 2 & com2 & 28 & $47 \%$ \\
\hline \multicolumn{5}{|l|}{ Quantité de fumier (t.ha $\left.{ }^{-1} \cdot \mathrm{an}^{-1}\right)$} \\
\hline minimum: $[0,15 ; 0,5[$ & 1 & fum1 & 34 & $57 \%$ \\
\hline maximum: $[0,5 ; 2]$ & 2 & fum2 & 26 & $43 \%$ \\
\hline \multicolumn{5}{|l|}{ Traitement phytosanitaire } \\
\hline non & 1 & tp1 & 8 & $13 \%$ \\
\hline Oui (au moins un au cours du cycle de la culture) & 2 & tp2 & 52 & $87 \%$ \\
\hline \multicolumn{5}{|l|}{ Fréquence de désherbage par an } \\
\hline 2 ou 3 fois & 1 & $\mathrm{fd} 1$ & 36 & $60 \%$ \\
\hline plus de 3 fois & 2 & $\mathrm{fd} 2$ & 24 & $40 \%$ \\
\hline
\end{tabular}


K.F. ZONGO et al. / Int. J. Biol. Chem. Sci. 10(1): 290-312, 2016

\begin{tabular}{|c|c|c|c|c|}
\hline \multicolumn{5}{|l|}{ Quantité NPK $\left(\mathrm{kg} \cdot \mathrm{ha}^{-1}\right)$} \\
\hline minimum: $[0 ; 10[$ & 1 & npk1 & 40 & $67 \%$ \\
\hline maximum :[10; 20] & 2 & npk2 & 20 & $33 \%$ \\
\hline \multicolumn{5}{|c|}{ Rendements céréales (t.ha ${ }^{-1}$ ) } \\
\hline minimum: $[0,1 ; 0,3[$ & 1 & $\operatorname{rdc} 1$ & 50 & $83 \%$ \\
\hline maximum: $[0,3 ; 0,6]$ & 2 & $\operatorname{rdc} 2$ & 10 & $17 \%$ \\
\hline \multicolumn{5}{|l|}{ Rendements niébé $\left(\right.$ t.ha $\left.^{-1}\right)$} \\
\hline minimum: $[0,05 ; 0,2[$ & 1 & $\operatorname{rdn} 1$ & 54 & $90 \%$ \\
\hline maximum: $[0,2 ; 0,4]$ & 2 & $\operatorname{rdn} 2$ & 6 & $10 \%$ \\
\hline
\end{tabular}

EA: exploitation agricole; $n$ : nombre d'exploitation agricole; CES/DRS: conservation des eaux et des sols et de défense restauration des sols;

CP: cordons pierreux, BE: bandes enherbées; DL: demi-lunes. 
Tableau 2 : Variables de statut social des exploitations agricoles.

\begin{tabular}{|c|c|c|c|c|}
\hline Statut social des EA & Notes & Indicateurs & Nombre d'EA & $\begin{array}{c}\text { Pourcentage d'EA } \\
(n=60)\end{array}$ \\
\hline \multicolumn{5}{|l|}{ Age de l'agriculteur (an) } \\
\hline$[27 ; 40[$ & 1 & ag1 & 11 & $18 \%$ \\
\hline$[40 ; 60]$ & 2 & ag2 & 31 & $52 \%$ \\
\hline$] 60 ; 78]$ & 3 & ag3 & 18 & $30 \%$ \\
\hline \multicolumn{5}{|l|}{ Nombre d'épouse } \\
\hline$[0 ; 2[$ & 1 & ne1 & 15 & $25 \%$ \\
\hline$[2 ; 3]$ & 2 & ne2 & 28 & $47 \%$ \\
\hline ]3; 5] & 3 & ne3 & 17 & $28 \%$ \\
\hline \multicolumn{5}{|l|}{ Scolarité } \\
\hline non & 1 & $\mathrm{sc} 1$ & 25 & $42 \%$ \\
\hline oui & 2 & $\mathrm{sc} 2$ & 35 & $58 \%$ \\
\hline \multicolumn{5}{|l|}{ Niveau de scolarisation } \\
\hline autre & 1 & $\mathrm{~ns} 1$ & 0 & $0 \%$ \\
\hline primaire & 2 & $\mathrm{~ns} 2$ & 35 & $58 \%$ \\
\hline \multicolumn{5}{|l|}{ Alphabétisé } \\
\hline non & 1 & al1 & 34 & $57 \%$ \\
\hline oui & 2 & $\mathrm{al} 2$ & 26 & $43 \%$ \\
\hline \multicolumn{5}{|l|}{ Langue d'alphabétisation } \\
\hline arabe & 1 & $\mathrm{~m} 1$ & 8 & $13 \%$ \\
\hline mooré & 2 & $\mathrm{~m} 2$ & 18 & $30 \%$ \\
\hline \multicolumn{5}{|c|}{ Nombre de bouche à nourrir } \\
\hline$[3 ; 10[$ & 1 & bn1 & 15 & $25 \%$ \\
\hline$[10 ; 20]$ & 2 & bn2 & 31 & $52 \%$ \\
\hline ]20; 50] & 3 & bn3 & 14 & $23 \%$ \\
\hline
\end{tabular}


Tableau 3 : Variables économiques des exploitations agricoles.

\begin{tabular}{|c|c|c|c|c|}
\hline Statut économiques des EA & Notes & Indicateurs & Nombre d'EA & Pourcentage d'EA \\
\hline & & & & $(\mathrm{n}=60)$ \\
\hline \multicolumn{5}{|l|}{ Nombre Total de Champs/EA } \\
\hline$[1 ; 3[$ & 1 & ntc1 & 29 & $48 \%$ \\
\hline$[3 ; 6[$ & 2 & ntc2 & 31 & $52 \%$ \\
\hline \multicolumn{5}{|l|}{ Superficie Totale /EA (ha) } \\
\hline$[1 ; 3[$ & 1 & stc1 & 8 & $14 \%$ \\
\hline$[3 ; 5]$ & 2 & stc2 & 41 & $68 \%$ \\
\hline$] 5 ; 14]$ & 3 & stc3 & 11 & $18 \%$ \\
\hline \multicolumn{5}{|l|}{$\begin{array}{l}\text { Nombre d'actifs agricoles (+12 } \\
\text { ans) }\end{array}$} \\
\hline$[1 ; 8[$ & 1 & naa1 & 33 & $55 \%$ \\
\hline$[8 ; 15]$ & 2 & naa2 & 17 & $28 \%$ \\
\hline ]15; 40] & 3 & naa3 & 10 & $17 \%$ \\
\hline \multicolumn{5}{|l|}{ Equipements agricoles } \\
\hline$[0 ; 1]$ & 1 & eqa1 & 12 & $20 \%$ \\
\hline$[2 ; 3]$ & 2 & eqa2 & 23 & $38 \%$ \\
\hline ]3; 4] & 3 & eqa3 & 25 & $42 \%$ \\
\hline \multicolumn{5}{|l|}{ Petits Ruminants } \\
\hline$[0 ; 10[$ & 1 & pr1 & 18 & $30 \%$ \\
\hline$[10 ; 20]$ & 2 & pr2 & 30 & $50 \%$ \\
\hline$] 20 ; 55]$ & 3 & pr3 & 12 & $20 \%$ \\
\hline \multicolumn{5}{|l|}{ Volailles } \\
\hline$[0 ; 10[$ & 1 & vo1 & 10 & $17 \%$ \\
\hline$[10 ; 20]$ & 2 & vo2 & 33 & $55 \%$ \\
\hline$] 20 ; 100]$ & 3 & vo3 & 17 & $28 \%$ \\
\hline \multicolumn{5}{|l|}{ Bovins d'élevage } \\
\hline Aucun & 1 & be1 & 42 & $70 \%$ \\
\hline$[1 ; 7]$ & 2 & be2 & 13 & $22 \%$ \\
\hline$] 7 ; 20]$ & 3 & be3 & 5 & $8 \%$ \\
\hline \multicolumn{5}{|l|}{ Activités secondaires } \\
\hline non & 1 & as1 & 18 & $30 \%$ \\
\hline oui & 2 & as2 & 42 & $70 \%$ \\
\hline \multicolumn{5}{|l|}{$\begin{array}{l}\text { Recettes monétaires } \\
\text { annuelles/EA (KFCFA) }\end{array}$} \\
\hline$[25 ; 100[$ & 1 & rae1 & 16 & $27 \%$ \\
\hline$[100 ; 300]$ & 2 & rae2 & 31 & $52 \%$ \\
\hline$] 300 ; 2$ 000] & 3 & rae3 & 13 & $22 \%$ \\
\hline
\end{tabular}

FCFA $=$ Franc de la Communauté Financière Africaine. $1 \mathrm{KFCFA}=1 \mathrm{FCFA} * 1000$. 
Tableau 4 : Typologie des systèmes de culture et caractéristiques socio-économiques associées.

\begin{tabular}{|c|c|c|c|c|}
\hline $\begin{array}{l}\text { Types de systèmes } \\
\text { de culture }\end{array}$ & $\begin{array}{c}\text { Peu intensif et peu aménagé } \\
\text { (G1) }\end{array}$ & $\begin{array}{c}\text { Peu intensif et aménagé } \\
\text { (G3) }\end{array}$ & $\begin{array}{c}\text { Intensif peu aménagé } \\
\text { (G2) }\end{array}$ & Intensif aménagé (G4) \\
\hline $\begin{array}{l}\text { Caractéristiques } \\
\text { techniques }\end{array}$ & $\begin{array}{c}\text {-Peu d'apport de } \\
\text { matière organique } \\
\left(<0,5 \mathrm{t} \mathrm{ha}^{-1} \mathrm{an}^{-1}\right) \\
\text {-Désherbage peu } \\
\text { fréquent } \\
(2 \text { à } 3 \text { par an }) \\
\text {-Peu ou pas de } \\
\text { structure de } \\
\text { conservation des } \\
\text { eaux et des sols } \\
\text { (zaï, cordons } \\
\text { Pierreux, } \\
\text { demi-lunes ou } \\
\text { Bandes enherbées })\end{array}$ & $\begin{array}{c}\text {-Peu d'apport de } \\
\text { matière organique } \\
\left(<0,5 \mathrm{t} \mathrm{ha}^{-1} \mathrm{an}^{-1}\right) \\
\text {-Désherbage peu } \\
\text { fréquent } \\
(2 \text { à } 3 \text { par an }) \\
\text {-Nombreuses } \\
\text { structures de } \\
\text { conservation des } \\
\text { eaux et des sols }\end{array}$ & $\begin{array}{c}\text {-Apport de } \\
\text { matière organique } \\
\left(\geq 0,5 \mathrm{t} \mathrm{ha}^{-1} \mathrm{an}^{-1}\right) \\
\text {-Désherbage } \\
\text { fréquent } \\
\text { (plus de } 3 \text { par an) } \\
\text {-Peu ou pas de } \\
\text { structure de } \\
\text { conservation des } \\
\text { eaux et des sols } \\
\text { (zaï, cordons } \\
\text { Pierreux, } \\
\text { demi-lunes ou } \\
\text { Bandes enherbées) }\end{array}$ & $\begin{array}{c}\text {-Apport de } \\
\text { matière organique } \\
\left(\geq 0,5 \mathrm{t} \mathrm{ha}^{-1} \mathrm{an}^{-1}\right) \\
\text {-Désherbage } \\
\text { fréquent } \\
\text { (plus de } 3 \text { par an) } \\
\text {-Nombreuses } \\
\text { structures de } \\
\text { conservation des } \\
\text { eaux et des sols }\end{array}$ \\
\hline
\end{tabular}




\section{DISCUSSION}

Typologie des systèmes de culture des associations céréales-légumineuses

Dans la région Nord du Burkina, 4 types de systèmes de culture des associations céréales-niébé ont été identifiés (Tableau 4). La gestion des nutriments et de l'eau des sols sont les 2 éléments discriminants de cette typologie. Il est pertinent de parler de gradient d'intensification pour caractériser ces systèmes de culture. Ce gradient se rapporte avant tout au niveau d'investissement en main d'œuvre que ce soit pour réaliser des désherbages manuels fréquents, pour collecter les fumiers, fabriquer les composts et installer les structures de conservation des eaux et des sols et de défense restauration des sols tels que les zaï, cordons-pierreux, bandes enherbées, demi-lunes, et non, comme il est souvent rapporté, pour les régions cotonnières par des niveaux d'investissement en intrants chimiques (Dugué et al., 2012).

Les rendements des cultures sont généralement faibles et comparables à ceux obtenus pour la région par Bambara et al. (2008) dans les systèmes traditionnels d'association céréales-niébé (Tableau 1). Les rendements des céréales (mil, sorgho) et les faibles rendements de niébé ne sont pas associés à un niveau spécifique de fertilisation et de gestion de l'eau. Par contre, les rendements les plus élevés de niébé correspondent aux situations où la présence de nombreuses structures de conservation des eaux et des sols a pu accroître la disponibilité en eau (Figure 4). Le potentiel de fixation symbiotique du niébé rend cette culture peu dépendante de l'azote du sol pour son alimentation (Bado et al., 2006). Selon les études de Zoundi et al. (2007) et Bambara et al. (2008) en zone soudano-sahélienne du Burkina, la non adoption des variétés améliorées et la faible densité du niébé dans l'association seraient aussi à l'origine des faibles rendements du niébé. Bambara et al.
(2008) précisaient que seulement $28 \%$ des poquets de l'association comportent du niébé.

Dans le cas du sorgho ou du mil, la dépendance à la fourniture minérale du sol est totale. Les faibles rendements ici rapportés pour le sorgho ou le mil ne sont pas étonnants puisqu'on se situe en général sur des sols très pauvres, tandis que $57 \%$ des EA utilisent des quantités de fumier inférieures à $0,5 \mathrm{tha}^{-1}$; les doses apportées ne dépassent guère $2 \mathrm{t} \mathrm{ha}^{-1}$. Barthes et al. (2015) rapportent qu'une amélioration du nombre de grains induite par un apport de nutriments peut entraîner une compétition pour l'eau en fin de cycle, affectant le nombre de grains et l'efficience des nutriments vis-à-vis du rendement du sorgho dans ces agro-systèmes.

\section{Typologie socio-économique et logique des systèmes de culture}

L'âge du chef d'exploitation influence son régime matrimonial (polygamie ou monogamie) et la taille de sa famille (Figure 5). La polygamie et la taille de la famille de l'exploitant agricole sont des indicateurs de sa richesse car ces femmes et sa progéniture servent de main d'œuvre familiale importante au cours des travaux champêtres. Les exploitants les plus âgés sont ceux qui ont les moyens économiques les plus importants (Figure 7). Contrairement à ce à quoi l'on pouvait s'attendre, les plus faibles recettes monétaires, moins de 100 KFCFA, sont associés au groupe intermédiaire et non au groupe le moins nanti économiquement (Figure 6). Ce résultat pourrait être lié à des stratégies différentes entre ces deux groupes vis-à-vis des investissements dans l'agriculture. Le groupe intermédiaire se distingue par la pratique d'une activité annexe; il pourrait s'agir d'un groupe qui se démobilise de l'agriculture au profit des activités comme l'orpaillage ou le commerce. Ces résultats sont proches de ceux obtenus par Chikowo et al. (2014) qui avaient montré que 
la taille des exploitations, la possession de bétail caractérisent la typologie des exploitations agricoles des villages du Kenya, de Malawi du Zimbabwé, et de Tanzanie. Mowo et al. (2006) ont trouvé les mêmes relations en Tanzanie.

Les groupes de systèmes de culture présentés ci-dessus sont associés à des niveaux socio-économiques différents (Tableau 4). Les exploitations agricoles peu intensives sont moins nanties sur le plan économique (Figure 8) et leurs chefs ont moins de 60 ans (Figure 7). Ces résultats sont en phase avec ceux de Chikowo et al. (2014) qui avaient montré en Afrique de l'Est que les différences dans la gestion de la fertilité organique des champs sont déterminées par la taille des exploitations agricoles et la possession de bétail. Les vieilles exploitations sont mieux nanties sur le plan de l'élevage et peuvent ainsi apporter plus de fertilisants organiques à leur champ. Des relations analogues avaient été établies par Somda et al. (2002) et Ouédraogo (2004) au Burkina Faso.

\section{Conclusion}

Cette étude a mis en évidence l'existence d'une diversité de systèmes de culture de l'association céréales-niébé dans la région Nord du Burkina Faso. Les principales composantes de cette diversité sont l'utilisation d'amendements organiques, la fréquence de désherbage, l'usage de techniques de conservations des eaux et des sols et de défense restauration des sols. L'investissement le plus important est majoritairement représenté par la main d'œuvre familiale. La diversité des systèmes de culture suit une logique socio-économique. En particulier, l'utilisation de matières organiques et la fréquence de désherbage de l'association vivrière sont en lien avec la disponibilité de main d'œuvre familiale, l'importance du cheptel, la superficie totale des champs et l'âge du champ désigné par l'âge du chef d'exploitation dans la région. Les exploitations agricoles les plus anciennes, telles qu'indiquées par l'âge du chef d'EA, sont les plus nanties vis-à-vis de ces critères. Ces exploitations ont un nombre d'épouses élevé, qui représente aussi une disponibilité d'une main d'œuvre féminine importante. Cette typologie des systèmes de culture est à prendre en compte dans une approche d'amélioration de ces systèmes notamment sur la gestion des fertilisants, la nature des techniques de conservation des eaux et des sols existants et sur certaines pratiques culturales en rapport avec les contextes socioéconomiques spécifiques de chaque type d'EA. En perspective, il s'avère aussi nécessaire d'appréhender l'influence des facteurs pédo-climatiques sur ces systèmes traditionnels d'association afin d'alimenter une ingénierie agronomique améliorant les rendements des cultures et la fertilité des sols.

\section{CONFLIT D'INTERETS}

Tous les auteurs ont pris connaissance de la dernière version du manuscrit et ont donné leur accord pour soumission ; ils ont aussi eu l'approbation de leurs organismes de tutelle. Les auteurs déclarent qu'ils n'ont aucun conflit d'intérêts.

\section{CONTRIBUTIONS DES AUTEURS}

KFZ a été l'investigateur principal ; EH a suivi la conception de l'étude et la collecte des données ; a participé à l'amélioration de la qualité scientifique du manuscrit; J-JD a contribué à l'amélioration de la qualité scientifique du manuscrit; DB a participé aux analyses, interprétations statistiques des données et la relecture du manuscrit; DM a participé à la correction du manuscrit ; CC-D a participé à l'analyse statistique des données, l'interprétation des tableaux et figures et la correction du manuscrit. 


\section{REMERCIEMENTS}

Nous tenons à remercier les populations des villages d'étude qui ont consacré un peu de leur temps précieux pendant la phase de collecte des données de l'enquête qui a coïncidé avec les travaux champêtres. Nos remerciements vont aussi à l'endroit de l'UFR-SVT de l'Université de Ouagadougou, de l'Institut de Recherche pour le Développement de Ouagadougou et de l'UMR Eco\&Sols de Montpellier-France pour l'accès aux moyens logistiques, informatiques et la forte contribution des co-auteurs issus de ces organismes à l'aboutissement de ce travail. Egalement, nous remercions Monsieur NEBIE et Monsieur KABRE qui nous ont aidés respectivement à la réalisation des dessins inclus dans le manuscrit et à la confection de la carte géographique de la zone d'étude.

\section{REFERENCES}

Affholder F, Poeydebat C, Corbeels M, Scopel E, Tittonell P. 2013. The yield gap of major food crops in family agriculture of the tropics: assessment and analysis through field surveys and modeling. Field Crop. Res., 143: 106-118. DOI: 10.1016/j.fcr.2012.10.021.

Aune JB, Bationo A. 2008. Agricultural intensification in the Sahel - The ladder approach. Agr. Syst., 98: http://dx.doi.org/119-125. DOI: 10.1016/j.agsy.2008.05.002.

Bambara D, Zoundi JS, Tiendrebeogo JP. 2008. Association céréale/légumineuse et intégration agriculture-élevage en zone soudano-sahélienne. Cah. Agric., 17(3): 297-301. DOI: 10.1684/agr.2008.0203.

Bado BV, Bationo A, Cescas MP. 2006. Assessment of cowpea and groundnut contributions to soil fertility and succeeding sorghum yields in the Guinean savannah zone of Burkina Faso
(West Africa). Biol. Fert. Soils, 43: 171176. DOI: 10.1007/s00374-006-0076-7.

Barthes BG, Penche A, Hien E, Deleporte P, Clermont-Dauphin C, Cournac L, Manlay JL. 2015. Effect of ramial wood amendment on sorghum production and topsoil quality in a Sudano-Sahelian ecosystem (central Burkina Faso). Agroforest. Syst., 89: 95-96. DOI: 10.1007/s10457-014-9759-5.

Bationo A, Waswa B, Abdou A, Bado BV, Bonzi M, Iwuafor F. 2012. Overview of Long term experiments in Africa. In Lessons Learned from Long Term Soil Fertility. Management Experiments in Africa, Bationo A, Waswa B, Kihara J, Adolwa I, Vanlauwe B, Saidou K (eds). Springer: Dordrecht; 1-26.

Bayala J, Sileshi GW, Coe R, Kalinganire A, Tchoundjeu Z, Sinclair F, Garrity D. 2012. Cereal yield response to conservation agriculture practices in drylands of West Africa: A quantitative synthesis. J. Arid Environ., 78: 13-25. DOI: /10.1016/j.jaridenv.2011.10.011.

Chikowo R, Zingore S, Snapp S, Johnston A. 2014. Farm typologies, soil fertility variability and nutrient management in smallholder farming in Sub-Saharan Africa. Nutr. Cycl. Agroecosys., 100:118. DOI: 10.1007/s10705-014-9632-y.

Clermont-Dauphin C, Blanchart E, LorangerMerciris G, Meynard JM. 2014. Cropping Systems to improve soil biodiversity and ecosystem services: The Outlook and Lines of Research. In Agroecology and Global Change, Sustainable Agriculture Reviews 14, Ozier-Lafontaine H, Lesieur-Jannoyer M (eds). Springer International Publishing: Switzerland.

Dabat MH, Lahmar R, Guissou R. 2012. La culture du niébé au Burkina Faso »une voie d'adaptation de la petite agriculture 
à son environnement ? Autrepart, 62: 95114. DOI: 10.3917/autr.062.0095.

Doamba SMF, Nacro HB, Sanon A, Sedogo M. 2011. Effet des cordons pierreux sur l'activité biologique d'un sol ferrugineux tropical lessivé (Province du Kouritenga au Burkina Faso). Int. J. Biol. Chem. Sci., 5(1) : 304-313. DOI : http://dx.doi.org/10.4314/ijbcs.v5i1.6810 6.

DPSAA, Direction de la Prospective et des Statistiques Agricoles et Alimentaires : Articles de la Direction des PSAA à des conférences scientifiques. 2011. Burkina Faso. 211p.

Dugué P, Autfray P, Blanchard M, Djamen P, Dongmo A. 2012. L'agro-écologie pour l'agriculture familiale dans les pays du Sud : impasse ou voie d'avenir ? Le cas des zones de savane cotonnière de l'Afrique de l'Ouest et du Centre. In René Dumont revisité et les politiques agricoles africaines, GRET (éd). Novembre 2012, Paris, France, p. 93. http://hal.cirad.fr/cirad-01066447.

FAO (Food and Agriculture Organization), 2000. La Base de données mondiale sur les sols: avantages et faiblesses pour la connaissance et l'utilisation des milieux édaphiques au Burkina Faso. In Quatorzième Réunion du Sous-Comité Ouest et Centre Africain de Corrélation des Sols pour la Mise en Valeur des Terres. Abomey, Benin, 9-13 Octobre 2000; 121-128. ftp://ftp.fao.org/docrep/fao/005/y3948F/, (consulté le 20/01/2015).

FAO (Food and Agriculture Organization), 2014. IUSS Working Group WRB. 2014. World Reference Base for Soil Resources 2014. International soil classification system for naming soils and creating legends for soil maps. World Soil Resources Reports, 106. FAO, Rome, pp 191. http://www.fao.org/3/a-i3794e.pdf, (consulté le 16/04/2015).

Hien E, Kabore WT, Masse D, Dugué P. 2010. Sustainable farming systems in the subsahelian zone of Burkina Faso-Key Factors. Sustainability in Debate (Special Issue Climate, Sustainability and Development in Semi-Arid Regions), 1(2): 127-140.

Fatondji D, Martius C, Vlek P. 2001. Zaï-a traditional technique for land rehabilitation in Niger. ZEF News, 8: 12.

Giller KE, Witter E, Corbeels M, Tittonell P. 2009. Conservation agriculture and smallholder farming in Africa: The heretics' view. Field Crop. Res., 114(1): 23-34. DOI:1 0.1016/j.fcr.2009.06.017.

Guinko S. 1998. Caractéristiques de la végétation du Burkina Faso et leurs impacts sur les sols. Tour B7 du 16è Congrès Mondial de science du sol. Ouagadougou, Burkina Faso, 13 p.

Kuentz Simonet V, Lyser S, Candau J, Deuffic P, Chavent M. 2013. Une approche par classification de variables pour la typologie d'observations : le cas d'une enquête agriculture et environnement. Société Française de Statistique et Société Mathématique de France. J. Soc. Fran. $\quad$ Stat., 154(2): 37-63. https://hal.archives-ouvertes.fr/hal00876254.

Koura BI, Dedehouanou H, Dossa HL, Kpanou BV, Houndonougbo F, Houngnandan P, Mensah GA, Houinato M. 2015. Determinants of crop-livestock integration by small farmers in Benin. Int. J. Biol. Chem. Sci., 9(5): 2272-2283. DOI: http://dx.doi.org/10.4314/ijbcs.v9i5.2

Lahmar R, Yacouba H, 2012. Zaï et potentiel de l'association cultures annuellesarbustes natifs. In La Grande Muraille Verte : Capitalisation des Recherches et Valorisation des Savoirs Locaux, Dia A, 
Duponnois R (éds). IRD: Marseille, France; 203-223. http://publications. cirad.fr/une_notice.php?dk=566476.

Mazzucato V, Niemeijer D. 2000. Rethinking soil and water conservation in a changing society: A case study in eastern Burkina Faso. PhD thesis, Wageningen Agricultural University, Netherlands, pp 380.

Mowo JG, Janssen BH, Oenema O, German LA, Mrema JP, Shemdoe RS. 2006. Soil fertility evaluation and management by smallholder farmer communities in Northern Tanzania. Agr. Ecosyst. Environ., 116 (1-2): 47-59. DOI: 10.1016/j.agee.2006.03.021.

Ondersteijn CJM, Giesen GWJ, Huirne RBP. 2003. Identification of farmers' characteristics and farm strategies explaining changes in environmental and economic performance of dairy farms. Agr. Syst., 78: 31-55. DOI: 10.1016/S0308-521X(03)00031-3.

Ouédraogo E. 2004. Soil quality improvement for crop production in semi-arid West Africa. PhD thesis, Wagenigen University, Netherlands, pp. 193.

Roose E, 2004. La gestion conservatoire de l'eau et de la fertilité des sols : une stratégie nouvelle de la lutte antiérosive pour le développement durable. Sécheresse, 15(1) : 5-7.

Sawadogo H, Laurent Bock L, Lacroix D, Zombré NP. 2008. Restauration des potentialités de sols dégradés à l'aide du zaï et du compost dans le Yatenga (Burkina Faso). Biotechnol. Agron. Soc. Environ., 12(3): 279-290. http://orbi.ulg.ac.be/jspui/handle/2268/33 221.

Serpantié G. 2009. L'agriculture de conservation à la croisée des chemins. Vertigo, Revue des Sciences et de l'Environnement, 9(3), 21p.
Somda J, Nianogo AJ, Nassa S, Sanou S. 2002. Soil fertility management and socio-economic factors in crop livestock systems in Burkina Faso: a case study of composting technology. Ecol. Econ., 43: 175-183.

Somé D, Hien E, Assigbetse K, Drevon JJ, Masse D. 2015 Dynamique des compartiments du carbone et de l'azote dans le sol cultivé en niébé et sorgho dans le système zaï en zone Nord soudanienne du Burkina Faso. Int. J. Biol. Chem. Sci., 9(2): 954-969. DOI: http://dx.doi.org/10.4314/ijbcs.v9i2.32.

Wopereis MCS, Tamélokpo A, Ezui K, Gnakpénou D, Fofana B, Breman H. 2006. Mineral fertilizer management of maize on farmer fields differing in organic inputs in the West African savanna. Field Crop. Res., 96: 355-362.

Zeinabou H, Mahamane S, Nacro HB, Bado BV, Lompo F, Bationo A. 2014. Effet de la combinaison des fumures organominérales et de la rotation niébé-mil sur la nutrition azotée et les rendements du mil au sahel. Int. J. Biol. Chem. Sci., 8(4): $\quad$ 1620-1632. DOI: http://dx.doi.org/10.4314/ijbcs.v8i4.24

Zougmoré R, Ouattara K, Mando A, Ouattara B. 2004. Rôle des nutriments dans le succès des techniques de conservation des eaux et des sols (cordons pierreux, bandes enherbées, zaï et demi-lunes) au Burkina Faso. Sciences et Changements Planétaires/Sécheresse, 15(1): 41-48.

Zoundi JS, Lalba A, Tiendrebeogo JP, Bambara D. 2007. Systèmes de culture améliorés à base de niébé (Vigna unguiculata (L.) Walp) pour une meilleure gestion de la sécurité alimentaire et des ressources naturelles en zone semi-aride du Burkina Faso. Tropicultura, 25(2): 87-96. DOI: 10.1016/j.fcr.2005.08.004 